\title{
Ethics as a Service: A Pragmatic Operationalisation of AI Ethics
}

\author{
Jessica Morley ${ }^{1} \mathbb{D} \cdot$ Anat Elhalal $^{2} \cdot$ Francesca Garcia $^{2} \cdot$ Libby Kinsey $^{2}$. \\ Jakob Mökander ${ }^{1} \cdot$ Luciano Floridi $^{1,3}$
}

Received: 16 February 2021 / Accepted: 1 June 2021 / Published online: 19 June 2021

(c) The Author(s) 2021

\begin{abstract}
As the range of potential uses for Artificial Intelligence (AI), in particular machine learning (ML), has increased, so has awareness of the associated ethical issues. This increased awareness has led to the realisation that existing legislation and regulation provides insufficient protection to individuals, groups, society, and the environment from AI harms. In response to this realisation, there has been a proliferation of principle-based ethics codes, guidelines and frameworks. However, it has become increasingly clear that a significant gap exists between the theory of AI ethics principles and the practical design of AI systems. In previous work, we analysed whether it is possible to close this gap between the 'what' and the 'how' of AI ethics through the use of tools and methods designed to help AI developers, engineers, and designers translate principles into practice. We concluded that this method of closure is currently ineffective as almost all existing translational tools and methods are either too flexible (and thus vulnerable to ethics washing) or too strict (unresponsive to context). This raised the question: if, even with technical guidance, AI ethics is challenging to embed in the process of algorithmic design, is the entire pro-ethical design endeavour rendered futile? And, if no, then how can AI ethics be made useful for AI practitioners? This is the question we seek to address here by exploring why principles and technical translational tools are still needed even if they are limited, and how these limitations can be potentially overcome by providing theoretical grounding of a concept that has been termed 'Ethics as a Service.'
\end{abstract}

Keywords Artificial Intelligence $\cdot$ Machine learning $\cdot$ Data ethics · Applied ethics · Business ethics

Jessica Morley

jessica.morley@oii.ox.ac.uk

1 Oxford Internet Institute, University of Oxford, 1 St Giles', Oxford OX1 3JS, UK

2 Digital Catapult, 101 Euston Rd, London NW1 2RA, UK

3 Alan Turing Institute, The British Library, 2QR, 96 Euston Rd, London NW1 2DB, UK 


\section{Introduction}

As the range of potential uses for Artificial Intelligence (AI), in particular machine learning (ML), has increased, so has awareness of the ethical issues posed by the design, development, deployment and use of AI systems (henceforth collapsed into 'Design'). Issues such as privacy, fairness, accountability, accessibility, environmental sustainability, and transparency are now not just discussed in academic literature but also in mainstream media. This increased awareness has led to the realisation that existing 'hard' governance mechanisms (such as legislation and other regulatory frameworks, e.g. ISO requirements) alone provide insufficient protection to individuals, groups, society, and the environment. Similarly, these mechanisms alone do not sufficiently incentivise the Design of socially preferable and environmentally sustainable AI. In an attempt to overcome these limitations, governments, private sector organisations, and others have focused on the development of 'soft' governance mechanisms such as ethics codes, guidelines, frameworks, and policy strategies (Redacted, 2018; Schiff et al., 2020). The development of these largely principle-based documents has been an important and necessary phase in the evolution of AI governance (Mulgan, 2019; Raab, 2020). However, it has become increasingly clear that highly abstract principles provide little protection from potential harms related to AI when AI practitioners have no guidance on how to design and deploy algorithms within these ethical boundaries (Clarke, 2019; Orr \& Davis, 2020). In other words, a significant gap exists between theory and practice within the AI ethics field (Ville et al., 2019). This is not unusual in ethics (consider for example the development of bioethics), where changes are sometimes theory-led, and can partly be explained by the relative 'newness' of the concept of AI ethical principles in the public policy domain ${ }^{1}:<20 \%$ of all the AI ethics documents are more than four-years old (Jobin et al., 2019). However, it may also be a result of the desire by influential private-sector organisations to 'ethics wash' (Floridi, 2019b) in an attempt to keep the ethics of AI a self-regulated field and delay legislative intervention (Butcher \& Beridze, 2019).

In previous work (Morley et al., 2019), we analysed whether it may be possible to start closing this gap between the 'what' and the 'how' of AI ethics by identifying the methods and tools already available to help AI developers, engineers, and designers (collectively 'practitioners' (Orr \& Davis, 2020)) know not only what to do or not to do, but also how to do it, or avoid doing it, by adopting an ethical perspective (Alshammari \& Simpson, 2017). We plotted the tools in a typology, matching them to ethical principles (beneficence, non-maleficence, autonomy, justice and explicability) and to stages in the algorithm development pipeline. Although we found that numerous tools and methodologies exist to help AI practitioners translate between the 'what' and the 'how' of AI ethics, we also found that the vast majority

\footnotetext{
1 Differentiating between public policy and research domains is important here. AI researchers have long been aware of the ethical implications of algorithms. Both Alan Turing and Norbert Wiener were writing on the topic as early as 1940. It has taken a longer time for policymakers, regulators and legislators to become interested in the topic.
} 
of these tools are severely limited in terms of usability. The development of these translational tools and methods may have been useful for enabling individual groups of researchers/companies to raise internal awareness of AI ethics and to examine different interpretations of ethical principles. However, this impact has not been sufficiently tested and the external validity of all the tools/methods identified remains questionable. There is, as of yet, little evidence that the use of any of these translational tools/methods has an impact on the governability of algorithmic systems. As such, we cannot yet know whether they help disadvantaged groups in society be heard and enabled to embed and protect their values in design tools, and then into the resultant AI systems. Consequently, we concluded that the existing translational tools and methods fail to operationalise AI ethics effectively. Almost all translational tools are either too flexible or too strict in the following sense (Arvan, 2018). When something (ethical tools, methods or guidelines) is too flexible it does little to protect against the risks of ethics shopping and ethics washing (Floridi, 2019b). In contrast, if the same something is too strict, and is implemented in a top-down and non-flexible way, it fails to account for the fact that sometimes there is no social consensus about what is the 'right' way to interpret or apply ethics or ethical principles - this instead depends on how aggregate views of society are collected and which voices are included (Allen et al., 2000; Baum, 2017). This overall conclusion (too flexible or strict) forces the AI ethics community to face the difficult question: if, even with technical guidance (such as that provided in IEEE's Ethically Aligned Design standards (The IEEE Global Intiative on Ethics of Autonomous and Intelligent Systems, 2019)) AI ethics is challenging to embed in the process of algorithmic Design, is the entire pro-ethical design (Floridi, 2019a) endeavour rendered futile? And, if no, then how can AI ethics be made useful for AI practitioners?

In the following pages, we seek to answer these questions by exploring why principles and technical translational tools are still needed even if they are limited, and how these limitations can be potentially overcome by providing theoretical grounding of a concept that has been termed 'Ethics as a Service'. 2 Specifically, the sections 'lowering the level of abstraction' and 'limits of principlism and translational tools' explain in more detail the limitations of principlism and existing translational tools and methods. The section titled 'a series of compromises' outlines the compromises that must be made to enable the practical operationalisation of AI ethics. The section 'Outlining Ethics as a Service' provides the theory underpinning the concept of 'Ethics as a Service'. The final section concludes the article, highlighting where further research is needed.

\footnotetext{
2 As will become clear through the development of the 'Ethics as a Service' concept in the following pages-our use of the concept is one grounded in the theory of Habermas's discourse ethics (Heath, 2014; Mingers \& Walsham, 2010; Rehg, 2015) and Floridi's distributed responsibility (Floridi, 2016). This makes our interpretation of the concept distinct from the technocratic interpretation espoused by Google and other large tech firms claiming that they can 'audit customers' AI systems for ethical integrity' (Simonite, 2020). This paper should not, therefore, be read as being in support of such claims.
} 


\section{Lowering the Level of Abstraction}

AI ethical guidance documents have been produced by a range of stakeholders, from technology companies, professional bodies and standards-setting bodies to governments and research organisations (Whittlestone et al., 2019). According to the Global Inventory of AI Ethics Guidelines, managed by Algorithm Watch, there are now more than 160 documents in existence (Alglorithm Watch, 2020). Whilst it is possible to summarise the principles contained within these documents as beneficence, non-maleficence, autonomy, justice and explicability (Floridi \& Cowls, 2019), the range of concepts covered is vast and includes transparency; fairness; responsibility; privacy; freedom; trust; sustainability; dignity and solidarity (Jobin et al., 2019).

This variation, and consequential confusion, is perhaps to be expected. Many of the ethical harms that the principles in these documents purport to protect against are poorly understood because they are described too vaguely (Clarke, 2019). The vagueness of statements such as 'AI systems may be discriminatory' results in broad and generic rather than deep and specific responses. Additionally, as Carrillo (2020, p. 3) explains: 'beyond the basic underlying principles and common elements, ethical conceptions and principles vary across traditions, cultures, ideologies, systems and countries. In the end, if the expression 'ethics' in itself is universal, the content of 'the ethical' evolves and includes variable and flexible standards in accordance with the evolution of times and societies.' The risks that arise from this lack of clear ethical guidance are many and include: ethics washing; ethics shopping; ethics dumping; ethics shirking and ethics lobbying (Floridi, 2019b). Hence, ethical principles have been accused of being too flexible (or too undefined) to be of practical use to AI practitioners (Mittelstadt, 2019; Whittlestone et al., 2019). The accusation is mistaken insofar as the ethical principles should be seen as providing the foundation and not the details of ethical practices, in a way comparable to what a Constitution does when compared to specific legislation. It would be mistaken to criticise the Constitution of a country for being of no direct practical use in the regulation of medical appliances, for example. This is why a promising and reasonable approach to the problem of not-yet actionable AI ethical principles is to bring ethical guidance down to the Design level, by providing tools and methods that translate the 'what' of AI ethics into the 'how' of technical specifications. In doing so we can hope to create a bridge between abstract principles and technical implementations (Hagendorf, 2020). This is the solution that we explored in our previous research (Morley et al., 2019) and it is also the solution Digital Catapult are exploring in practice with the Digital Catapult AI Ethics Framework ${ }^{3}$ (Box 1). In both this theoretical and applied work, we have concluded that this lowering of abstraction is, at best, a partial solution. Whilst translational tools and methods do help to lower the level of abstraction, they leave a number of other issues unresolved, and can be manipulated by reprehensible actors (Aïvodji et al., 2019).

\footnotetext{
${ }^{3}$ LF is chair of Digital Catapult's Independent Ethics Board. LK, EA and FG were employees of Digital Catapult at the time of writing. JM's work on applied AI ethics is partially funded by Digital Catapult.
} 
In the following section we explore the limitations of translational tools in more detail. The Digital Catapult AI Ethics Framework (Box 1) can be considered an illustrative example of what we mean by 'translational tool'. The discussion is deliberately generalised and we recognise that some of the limitations we discuss can be overcome by combining the use of translational tools with other offerings. For example, the Digital Catapult's AI Ethics Framework is offered alongside more hands-on ethics consultations. This should be kept in mind so that we do not appear too critical and so that the motivation for us expanding on the concept of 'Ethics as a Service' in Sect. 5 is clear.

\section{Limits of Principlism and Translational Tools}

The first limitation to highlight, is that translational tools and methods are extraempirical. This means, as explained by Fazelpour and Lipton (2020), that they may set standards against which algorithmic practices are assessed, without themselves being subject to empirical evaluation. This leaves the translational tools vulnerable to manipulation. AI practitioners may choose the translational tool that aligns with what is for them the most convenient epistemological understanding of an ethical principle, rather than the one that aligns with society's preferred understanding (Krishnan, 2019). For example, certain types of 'explanation' can be used to obfuscate rather than illuminate (Aïvodji et al., 2019) patterns of injustice. In short, stated motivations for using a specific translational tool might not reflect actual motivation (Schiff et al., 2020).

Second, many of the existing translational tools and methods are 'diagnostic' but not 'prescriptive'. For example, they might identify whether a dataset is biased, but offer very little support to AI practitioners on how to overcome the issue. Others, as McMillan and Brown (2019) indicate, present 'technical fixes' to what are in essence socially-derived harms. Furthermore, when the parameters for the 'diagnosis' of fairness, transparency or accountability are set by the AI practitioners themselves, the potential for objective critique is easily lost and so the aim of the translational tool or method ceases to 'ensure the algorithmic system meets the criteria of social preferability' (Floridi \& Taddeo, 2016) (and therefore ethical justifiability). Instead, the aim of the translational tool or method becomes to 'ensure the algorithmic system meets the practitioner's optimal criteria' (Terzis, 2020). As Martin (2019, p. 842) attests 'delegating a task to a technology [in this instance a 'translational' tool or method] does not remove the associated responsibility for that task. It is [still] a value-laden decision...' In short, according to Fazelpour and Lipton, (2020, p. 58), when used in this way, translational tools and methods: (a) can lead to systematic neglect of some [unethical] injustices and distort our understanding of others; (b) do not by themselves offer sufficient practical guidance about what should be done, sometimes leading to misguided mitigation strategies; (c) do not, by themselves, make clear who, among decision-makers is responsible for intervening to right specific [unethical]injustices (our additions in brackets).

Finally, too often these translational tools are positioned or perceived by AI practitioners as a 'one-off' test: something that just needs to be completed for 
compliance purposes and then forgotten about. This encourages ethics by 'tick-box' and introduces the risk of writing ethics into the business case and coding them out by the time the algorithmic system is deployed (Morley et al., 2019). Instead, the ethical implications of an algorithmic system should be regularly evaluated, at a minimum as part of three distinct phases: validation, verification and evaluation. The first phase (validation) is concerned with whether the right algorithmic system is being developed; the second phase (verification) is concerned with whether the algorithmic system is being developed in the right way; and the third phase (evaluation) is concerned with whether the algorithmic system is continuing to operate in the right way once deployed, needs to be revised, or can be improved (redacted). Thus, unless ethical evaluation becomes an integral part of a system's operation (Arnold \& Scheutz, 2018), there is no guarantee that pro-ethical translational tools will have any positive impact on the ethical implications of AI systems. Indeed, they could have a negative impact by fostering a false sense of security and consequential complacency.

This critique of AI ethics principlism and translational tools and methods raises the question whether the entire pro-ethical design endeavour is futile, if even with technical guidance, AI ethics is difficult or impossible to embed in the process of algorithmic design, development, deployment, and use. However, the experience of other applied ethics fields (for example, medical ethics and research ethics) shows that it is possible to operationalise abstract ethical principles successfully for the purpose of protecting individuals, groups, society and the environment from particular social harms and incentivising the best outcomes. The effort is not futile. With this reassurance in mind, the next pertinent question becomes: how can AI ethics be usefully operationalised for AI practitioners? The next section offers a way forward.

\subsection{Box 1: The Digital Catapult Al Ethics Framework}

The DCEF was developed by the Digital Catapult's independent ethics board following consultation with a number of Digital Ethicists and other experts. The framework consists of four levels, and is intended to help AI start-ups working with the Digital Catapult to define and translate, transparently and contextually, high-level ethical principles into practice. The first level, therefore, consists of the five unifying high-level principles identified by Floridi et al., (2018): beneficence, non-maleficence, autonomy, justice, explicability. The second level consists of seven interpretations (or contextual definitions) of these principles identified through documentary analysis consultation with AI practitioners and those affected by AI systems. The third level operationalises Habermas's concept of discourse ethics (Buhmann et al., 2019), i.e. an approach that seeks to establish normative values and ethical truths through open discourse, and consists of a series of questions that are designed to encourage AI practitioners to conduct ethical foresight analysis (Floridi \& Strait, 2020). The fourth level provides access to more practical, and less discursive tools e.g. python libraries designed to identify bias in data. The connections between the levels are shown below. Companies 
using the DCEF to translate high-level ethical principles into practice are encouraged to consult it at validation, verification and evaluation stages of their product development pipeline, to ensure that at each stage time is dedicated to thinking through the ethical implications of all decisions made. This discussion is supported by members of the independent ${ }^{4}$ ethics board through consultations which also provide a vehicle for reviewing the efficacy of the Framework itself.

\begin{tabular}{|c|c|c|c|c|c|}
\hline L1 & $\begin{array}{l}\text { Beneficence: } \\
\text { promoting } \\
\text { well-being, pre- } \\
\text { serving dignity, } \\
\text { and sustaining } \\
\text { the planet }\end{array}$ & $\begin{array}{l}\text { Non-maleficence: } \\
\text { privacy, } \\
\text { security and } \\
\text { 'capability cau- } \\
\text { tion.' }\end{array}$ & $\begin{array}{l}\text { Autonomy: } \\
\text { the power } \\
\text { to decide } \\
\text { (whether to } \\
\text { decide) }\end{array}$ & $\begin{array}{l}\text { Justice: promot- } \\
\text { ing prosperity } \\
\text { and preserving } \\
\text { solidarity }\end{array}$ & $\begin{array}{l}\text { Explicability: } \\
\text { enabling the } \\
\text { other principles } \\
\text { through intel- } \\
\text { ligibility and } \\
\text { accountability }\end{array}$ \\
\hline L2 & $\begin{array}{l}\text { Be clear about } \\
\text { the benefits of } \\
\text { the product or } \\
\text { service } \\
\text { Consider the } \\
\text { business model }\end{array}$ & $\begin{array}{l}\text { Know and man- } \\
\text { age the risks } \\
\text { Use data respon- } \\
\text { sibly }\end{array}$ & $\begin{array}{l}\text { Be open and } \\
\text { understandable } \\
\text { in communica- } \\
\text { tions }\end{array}$ & $\begin{array}{l}\text { Promote diver- } \\
\text { sity, equality } \\
\text { and inclusion }\end{array}$ & Be worthy of trust \\
\hline L3 & $\begin{array}{l}\text { For example: } \\
\text { What are the } \\
\text { goals, purposes } \\
\text { and intended } \\
\text { applications of } \\
\text { the product or } \\
\text { service? } \\
\text { Who or what } \\
\text { might ben- } \\
\text { efit from the } \\
\text { product/ser- } \\
\text { vice? Consider } \\
\text { all potential } \\
\text { groups of } \\
\text { beneficiar- } \\
\text { ies, whether } \\
\text { individual } \\
\text { users, groups } \\
\text { or society and } \\
\text { environment as } \\
\text { a whole }\end{array}$ & $\begin{array}{l}\text { For example } \\
\text { Is the training } \\
\text { data appropri- } \\
\text { ate for the } \\
\text { intended use? } \\
\text { Have potential } \\
\text { biases in the } \\
\text { data been } \\
\text { examined, } \\
\text { well-under- } \\
\text { stood and } \\
\text { documented } \\
\text { and is there a } \\
\text { plan to mitigate } \\
\text { against them? }\end{array}$ & $\begin{array}{l}\text { For example: } \\
\text { Does the com- } \\
\text { pany communi- } \\
\text { cate clearly, } \\
\text { honestly and } \\
\text { directly about } \\
\text { any potential } \\
\text { risks of the } \\
\text { product or } \\
\text { service being } \\
\text { provided? } \\
\text { Are the com- } \\
\text { pany's policies } \\
\text { relating to } \\
\text { ethical princi- } \\
\text { ples available } \\
\text { publicly and } \\
\text { to employ- } \\
\text { ees? Are the } \\
\text { processes to } \\
\text { implement and } \\
\text { update the poli- } \\
\text { cies open and } \\
\text { transparent? }\end{array}$ & $\begin{array}{l}\text { For example: } \\
\text { Are there pro- } \\
\text { cesses in place } \\
\text { to establish } \\
\text { whether the } \\
\text { product or } \\
\text { service might } \\
\text { have a negative } \\
\text { impact on the } \\
\text { rights and } \\
\text { liberties of } \\
\text { individuals or } \\
\text { groups? } \\
\text { Does the com- } \\
\text { pany have a } \\
\text { diversity and } \\
\text { inclusive- } \\
\text { ness policy } \\
\text { in relation to } \\
\text { recruitment } \\
\text { and retention of } \\
\text { staff? }\end{array}$ & $\begin{array}{l}\text { For example: } \\
\text { Is there a process } \\
\text { to review and } \\
\text { assure the integ- } \\
\text { rity of the AI } \\
\text { system over time } \\
\text { and take remedia } \\
\text { action if it is } \\
\text { not operating as } \\
\text { intended? } \\
\text { Does the company } \\
\text { have a clear } \\
\text { and easy to use } \\
\text { system for third } \\
\text { party/user or } \\
\text { stakeholder con- } \\
\text { cerns to be raised } \\
\text { and handled? }\end{array}$ \\
\hline L4 & \multicolumn{5}{|c|}{$\begin{array}{l}\text { See: https://www.digicatapult.org.uk/for-startups/other-programmes/applied-ai-ethics-typology } \\
\text { The full framework is available here: https://www.digicatapult.org.uk/for-startups/other-progr } \\
\text { ammes/ai-ethics-framework }\end{array}$} \\
\hline
\end{tabular}

\footnotetext{
${ }^{4}$ By 'Independent' we mean board where none of the members are employees of the AI company in question but are still embedded within the company to a sufficient degree as to be able to have access to necessary documentation, data and code, and understanding of the socio-technical context ('International AI Ethics Panel Must Be Independent', 2019; Raji et al., 2020). If necessary, this can be managed by placing the board members under non-disclosure agreements.
} 


\section{A Series of Compromises}

Thus far we have seen that the need to Design AI solutions pro-ethically is well recognised, and that the field of AI-ethics now has a solid foundation comprised of principle-based governing documents and translational tools and methods. Developing this foundation has been essential and the individual components remain highly valuable. However, pro-ethical Design practices remain difficult to operationalise practically as the Goldilocks Level of Abstraction has not yet been found. Attempts thus far remain either too flexible or too strict. To overcome these limitations, the 'just right' Level of Abstraction needs to be identified by making a series of compromises.

\subsection{Finding a Compromise Between Too Flexible and Too Strict}

Raab (2020) argues that when prescriptive guidelines are implemented in a topdown and non-flexible fashion, this gives the misleading impression that it is possible to take a formulaic approach to the application of ethical norms, principles and general rules to specific instances. In reality, the argument continues, applied ethics requires judgement. Specifically, it requires an ability to consider how risks, conflicting rights and interests, and social preferability varies depending on a particular context. The ethical implications of deploying an AI system in a healthcare setting are unlikely to be the same as the ethical implications of deploying an AI system in an educational setting. Similarly, the boundaries of social preferability within Europe may not be the same as the boundaries within Asia and these boundaries may change with time or with type of algorithm, or even with stage of development. Finally, ethical guidelines that are too strict portray algorithmic systems as static products of code and data that once deployed continue to operate in the same way as intended and have only the intended (positive) effects. Ananny and Crawford (2018) point out the reality is that algorithmic systems are assemblages of human and nonhuman actors which have many non-deterministic impacts. To understand (and therefore govern) the ethical implications requires understanding how the whole system works-including what may happen once the system is deployed and used by entities, or for purposes, other than the original practitioners or stated purpose.

With this in mind, if AI ethics is to be operationalised in a way that is useful to AI practitioners and simultaneously protective of individuals, groups, society and the environment, then the operationalisation must: (a) happen at the appropriate Level of Abstraction (where translational tools are neither too flexible, nor too strict); and (b) must not consist solely of a one-off tick-box exercise completed only at the beginning of the Design process. Developing a practical proethical Design approach that meets these two criteria is not simple, but it is not impossible. It requires a shift in the way that AI ethics is framed. The practice of AI ethics should not be seen as an end-goal that can be objectively achieved, observed, quantified, or compared. Instead it should be seen as a reflective development process, which also aims to help AI practitioners understand their 
own subjectivity and biases within a given set of circumstances (Terzis, 2020). By enabling the development of this understanding, a reflective process can help illuminate why unethical outcomes may occur so that the appropriate mitigation or avoidance strategy can be put in place (Fazelpour \& Lipton, 2020). From this perspective, the practical operationalisation of AI ethics becomes less about the paternalistic imposition of inflexible standards that ignore context and more about procedural regularity and public reason that can be adapted and shared across contexts and societies (Binns, 2018; Kroll et al., 2017). In practice, structured identification and transparent communication of tradeoffs help organisations arrive at resolutions that, even when imperfect, are at least publicly defensible (Whittlestone et al., 2019).

An operationalisation of AI ethics focused on procedural regularity and public reason would commit a company producing algorithmic systems to:

(a) justifying all design decisions to a set of common principles agreed through an inclusive and discursive process that involves all individuals, groups and environmental representatives likely to be directly or indirectly affected by the AI products of a specific company or research group. These principles should be reviewed periodically (e.g., annually);

(b) following a set and repeatable procedure to define and translate each of the agreed upon principles into technical standards in a way that achieves an acceptable level of ethical justifiability and environmental sustainability within the specific context; and

(c) ensuring appropriate oversight is in place at the validation, verification and evaluation stages.

Companies operationalising AI ethics in this way would use translational tools and ethical principles in the same way each time (and at repeated intervals to cover validation, verification, evaluation) but accept that the exact way in which they are applied is contextually dependent. This kind of shift away from abstract rules towards negotiated ethics has already been seen in arguments for a move from privacy by design to privacy engineering. Privacy engineering, as described by Alshammari and Simpson (2017, p. 162), is a 'means of applying engineering principles and process in developing and maintaining systems in a systematic and repeatable way, with a view to achieving acceptable levels of privacy protection' without assuming that the way that this is achieved will be the same in each instance or immutable through time or different contexts. Additionally, this approach to operationalisation covers the five pillars of good ethical governance set out by Winfield and Jirotka (2018) by turning AI ethics into a 'collaborative process, developed and iteratively (re)configured through material practices and continued negotiations' (Orr \& Davis, 2020, p. 731). However, if the responsibility for the whole process still sits with just the AI practitioners themselves, there remains a risk that the operationalisation process itself becomes subject to manipulation and may be used solely for ethics washing purposes. 


\subsection{Finding a Compromise Between Devolved and Centralised Responsibility}

One often highlighted option for avoiding these potential issues-derived from a lack of accountability and transparency - is to rely on external algorithmic audits $^{5}$ (Holstein et al., 2018; Mökander et al., forthcoming). In theory, the process described above could be managed internally by the company in question but audited by a third party (Mökander et al., forthcoming). Several auditing mechanisms have been proposed as means of examining the inputs and outputs of algorithms for bias and other harms (Cath, 2018; Sandvig, 2014). For example, 'Aequitas' is an open source toolkit which audits algorithms for bias and fairness (Saleiro et al., 2018) and 'Turingbox' is a proposed platform that would audit the explainability of an algorithmic system (Epstein et al., 2018). As these technical methods, and more human-based methods such as 'sock-puppet' auditing (Sandvig, 2014), have gained visibility, the perceived importance of the role they will play in ethical governance has also increased. In the UK, for example, the Information Commissioner's Office is developing an AI auditing framework that seeks to ensure organisations have measures in place to be compliant with data protection requirements, and mitigate risks associated with (amongst other issues) fairness, accuracy, security, and fundamental rights (Binns, 2018). Similarly, auditing firm PwC includes ethical audit as a key component of its responsible AI Framework (Oxborough et al., 2019). It is clear, therefore, that external ethical auditing will be a key component of any form of operationalised AI ethics.

However, there remain limitations. Proposed external auditing mechanisms typically focus on specific parts of the system, rather than looking at the overall system function (Cath, 2018), and so do little to address the risks of 'unpredictability' described above. Audits cannot guarantee to reveal all aspects of a system (Kroll, 2018), and so may miss the inputs that are the most harmful. In addition, they are typically conducted after a system has already been deployed, and so may have already had a negative impact (Raji et al., 2020). And, finally, audits may be rendered not viable without legislative change due to legal concerns regarding protection of consumer data or trade secrets (Katyal, 2019; Kroll et al., 2017). Moreover, it is difficult to quantify indirect externalities that accumulate over time (Rahwan, 2018). External auditors may therefore not only lack access but also resources, know-how and computational power to review AI systems (Kroll, 2018). Raji et al. (2020) discuss these limitations in detail and also note that the agile nature of AI development and typical lack of documentation challenges auditability. Furthermore, they stress how the lack of foresight analysis typically included in external post-hoc audits minimises the chances for audits to prevent future harms. They argue that internal audits, conducted by a dedicated team of organisational employees - but not the AI practitioners themselves - with full access to data and a focus on ethical foresight could be a pragmatic alternative. There is certainly some promise in this proposal.

\footnotetext{
5 We recognise that currently the word 'audit' is often used in a rather loose and confusing manner. In this context we simply define audit as 'a structured process whereby an entitles' present or past behaviour is assessed for consistency with relevant principles or norms' (Brundage et al., 2020).
} 
Code review and internal checks for reliability and robustness are already common practices within software engineering. Furthermore, internal auditing of this nature would mitigate the risks associated with external auditing (or fully-external ethical review boards) of ethically desensitising, de-skilling, and de-responsabilising company employees, and instead force companies to make their own critical choices and assume explicit responsibilities (Floridi, 2016). Yet, it is also undeniable that internal auditors may face conflicts of interest that make it hard for them to maintain an independent and objective opinion (Raji et al., 2020). This is especially true when there are currently limited incentives for companies to rigorously examine the implications behind technologies that are both profitable and powerful (Katyal, 2019). Thus, just as it was necessary to find a compromise between mechanisms that are too flexible or too strict, it seems that there is also a need to find a compromise between completely devolved and completely centralised responsibility for holding the ethical governance process itself accountable.

The solution here lies in the creation of a multi-agent system where the responsibility is distributed across different agents (individuals, companies) in a way that (a) aggregates the possibly good actions, so that the latter might reach the critical mass necessary to make a positive difference to the targeted environment and its inhabitants, and (b) isolates possibly negative actions (e.g., attempts to ethics wash), so that they never reach the necessary threshold to breach the fault-tolerance level of the overall system and undermine its effectiveness as an ethical governance mechanism (Floridi, 2013, 2016). This may seem overly theoretical, but it is actually a practically feasible approach, and a pragmatic analogy can be found in cloud computing, as explained in the next section.

\section{Outlining Ethics as a Service}

Cloud computing, the on-demand delivery of various computing services over the internet, has three models of service: Software as a Service (SaaS), Infrastructure as a Service (IaaS), and Platform as a Service (PaaS).

Software as a Service is the model of cloud computing that consumers are most readily familiar with. All aspects of the service are managed by a third-party, there are few customisation opportunities, and often there is a high risk of vendor lockin. In our analogy regarding AI ethical governance, this would represent the fully devolved model of governance (and one that is too strict). A third party would be responsible for dictating the set of ethical principles, for outlining the process that must be followed at each of the validation, verification, evaluation stages, and for conducting an ethical audit to see whether the process was followed correctly and whether this resulted in the expected positive outcomes.

Infrastructure as a Service, in comparison, represents the fully centralised governance model (and one that is too flexible). In cloud computing, servers, network operating systems, and storage are all provided via a dashboard or application programme interface (API), so that users have complete control over the entire infrastructure. In terms of ethical governance, this would involve the AI practitioners being responsible for both developing the AI ethics principles as well as 


\begin{tabular}{|c|c|c|c|}
\hline & $\begin{array}{l}\text { Centralised Responsibility (too } \\
\text { flexible) } \\
\text { (Infrastructure as a Service) }\end{array}$ & $\begin{array}{l}\text { Distributed Responsibility } \\
\text { (Ethics as a Service) } \\
\text { (Platform as a Service) }\end{array}$ & $\begin{array}{l}\text { Devolved Responsibility (too } \\
\text { strict) } \\
\text { (Software as a Service) }\end{array}$ \\
\hline Internal Responsibility & $\begin{array}{l}\text { Developing ethical Code and } \\
\text { contextually defining meaning of } \\
\text { each principle } \\
\text { Evaluating selecting and using } \\
\text { translational tools and methods } \\
\text { Conducting ethical review of own } \\
\text { product at } 3 \text { stages and including } \\
\text { ethical foresight analysis } \\
\text { Auditing AI systems for ethical } \\
\text { compliance and social impact }\end{array}$ & $\begin{array}{l}\text { Contextually defining meaning } \\
\text { of each principle within the } \\
\text { ethical Code } \\
\text { Selecting and using translational } \\
\text { tools/methods from a pre- } \\
\text { approved list of available } \\
\text { translational tools/methods } \\
\text { Conducting ethical review of } \\
\text { own product at } 3 \text { stages and } \\
\text { including ethical foresight } \\
\text { analysis }\end{array}$ & $\begin{array}{l}\text { Using the translational } \\
\text { tools/methods they are told to }\end{array}$ \\
\hline External Responsibility & $\mathrm{N} / \mathrm{A}$ & $\begin{array}{l}\text { Developing ethical Code, } \\
\text { regularly reviewing it and } \\
\text { developing a set process that AI } \\
\text { practitioners must follow to } \\
\text { contextually define principles } \\
\text { Evaluating available translational } \\
\text { tools/methods and compiling a } \\
\text { pre-approved list available for } \\
\text { selection and use by the internal } \\
\text { AI practitioners and developing a } \\
\text { process that AI practitioners } \\
\text { must follow to contextually to } \\
\text { select which of the pre-approved } \\
\text { translational tools/methods they } \\
\text { will use } \\
\text { Auditing AI systems for ethical } \\
\text { compliance and social impact }\end{array}$ & $\begin{array}{l}\text { Developing ethical Code and } \\
\text { contextually defining the meaning } \\
\text { of each principle included in the } \\
\text { code. } \\
\text { Evaluating and dictating exactly } \\
\text { which translational tools and } \\
\text { methods can be used by the } \\
\text { internal AI practitioners } \\
\text { Conducting ethical review of } \\
\text { product at } 3 \text { stages and including } \\
\text { ethical foresight analysis as part } \\
\text { of overall auditing of AI systems } \\
\text { for ethical compliance and social } \\
\text { impact }\end{array}$ \\
\hline
\end{tabular}

Fig. 1 Comparison of distributions of responsibility for ethics-related activities in different AI ethics governance models. Centralised responsibility and devolved responsibility models represent the status quo, the Ethics as a Service model is the new proposal

the process to follow internally with limited meaningful engagement with external stakeholders. The AI practitioners would also be responsible for conducting internal audits.

Finally, there is Platform as a Service which represents the compromises we have outlined above. It is the Goldilocks option found between methods that are too flexible and strict, and between devolved governance and centralised governance. In the world of cloud computing, PaaS represents a set-up where the cloud provider provides the core infrastructure, such as operating systems and storage, but users have access to a platform that enables them to develop custom software or applications. These three options are summarised in Fig. 1.

In the world of AI ethical governance, Ethics as a Service-based on Platform as a Service model-could involve several components including, but not necessarily limited to: an independent multi-disciplinary ethics board; a collaboratively developed ethical code; and AI practitioners themselves. Responsibility could then be distributed across these components thus: 
1. Independent multi-disciplinary ethics advisory board responsible for providing the core infraethics as described:

a. The development of a principle-based ethical code through a process of discussion and negotiation that treats ethical patients (i.e. individuals, businesses and environments that may be impacted by the systems produced by the AI company in question) as real interlocutors, who can genuinely impact the design of the system (Aitken et al., 2019; Arvan, 2018; Durante, 2015).

b. The setting out of a process that needs to be followed at validation, verification and evaluation stages of algorithmic Design to ensure pro-ethical design by: (i) defining contextually the specific meaning of each of the principles in the ethical code; and (ii) providing an appropriate range of proven-effective translational tools which can be selected to translate from principles to practice, according to the contextually specific definitions. This process and selection of translational tools must include an element of ethical foresight analysis (Floridi \& Strait, 2020), and mechanisms for closing down, and rectifying the consequences of a system that is found to be in breach of the principles (Morley et al., 2020). It must also recognise that positive, ethical features are open to progressive increase, that is an algorithm can be increasingly fair, and fairer than another algorithm or a previous version, but makes no sense to say that it is fair or unfair in absolute terms (compare this to the case of speed: it makes sense to say that an object is moving quickly, or that it is fast or faster than another, but not that it is fast in absolute terms).

c. Conducting regular audits of the whole behaviour of the company-not just the end product once launched - to see whether it is genuinely committed to ethical conduct; whether AI practitioners are following the defined process; and whether the final output is ethically justifiable according to contextuallydefined principles.

2. The internal company employees (the AI practitioners themselves) responsible for providing the 'customised software,' namely:

a. Contextually defining the principles;

b. Identifying the appropriate tools, and putting them to use whilst designing a specific algorithmic system;

c. Documenting how the process was followed, in public, and justifying why specific decisions were made, when and by who.

In theory, distributing the responsibility for operationalising AI ethics in this manner may overcome many (although definitely not all) of the limitations of current approaches described above. However, whether it works in practice is yet to be seen. It is also important to note that, because AI systems learn and update their internal decision-making logic over time, code-audits (as described in 1c above) need to be complemented with continuous functionality and impact audits. However, such audits inevitably impose both financial and administrative costs (Brundage et al., 2020). Care should therefore be taken to not put undue 
burden on certain sectors in society (Koene et al., 2019). One way to balance the need for audits with incentives for innovation is to introduce a progressive level of AI governance that is proportional to the risk level associated with a specific combination of technology and context. Therefore, testing of the concept must involve experimentation to find the proportionate degree of oversight for different AI solutions. For this reason (and others), further research is urgently needed on how to evaluate translational tools and, in doing so, evaluate the current impact of the AI ethics endeavour in order to highlight further ways in which it could be improved. To start this research, a partial pilot of "Ethics as a Service," which includes the Digital Catapult AI Ethics framework (Box 1), ethics consultations and an Independent multi-disciplinary ethics advisory board is being trialed by Digital Catapult. We would encourage others to develop partial or complete pilots of the concept, so that answers to the following questions might be developed: how should members of the independent ethics board be selected; should members of the board be paid for their time or would this introduce conflicts of interest; should the independent ethics board be the same group who conducts the audit, or would this introduce problematic incentives to make their work appear more successful than it is in reality; where does the responsibility sit for deciding to stop development of an AI solution if it is found to be harmful; how does the implementation of Ethics as a Service vary between companies of different sizes (e.g., start-up vs. large established company) and working in different sectors; how do the benefits/drawbacks vary in these different contexts? We would ask that those working on these, and other questions, publicly report on the successes and failures so that a commons of knowledge related to 'best ethical practice' can be established.

\section{Conclusion}

As Thomsen (2019) states, 'ethics for AI cannot be expected to be any simpler than ethics for humans.' Indeed, it may be more complicated, since it adds to it further technical issues. Research ethics and medical ethics have always involved a combination of the law, ethical governance policies, practices, and procedures, with contextual discursive and procedural support. This combination approach has enabled these branches of applied ethics to find a good balance between being too strict and too flexible, and between too centralised and too devolved. Therefore, it seems reasonable to hypothesise that AI ethics would benefit from an equally customisable approach, and that if this balance can be achieved then the pro-ethical Design endeavour may succeed. At the very least shifting the focus of AI ethics away from principles to procedural regularity will make AI ethics seem more relatable to AI practitioners. Encouraging a procedural approach can, for example, help make the parallels between AI ethics and other quality assurance processes, such as safety testing, clearer and thus make it more obvious why careful consideration needs to be given to each Design decision. We hope that the idea of Ethics as a Service, as outlined in the article, has at least highlighted this. 
Whilst these opportunities for moving forward the conversation about AI ethics and the role that Ethics as a Service may play in this, should be celebrated, it must be acknowledged that the impacts of AI systems cannot be entirely controlled through technical design (Orr \& Davis, 2020).

Biased AI is not simply the result of biased datasets, for example. AI solutions themselves are complex and are then deployed into complex systems. In complex systems, agents interact with each other and with other systems in unexpected ways, making their response to change unpredictable and non-linear. It is, therefore, likely that we will genuinely not know whether any approaches to 'pro-ethical' Design have made an impact (positive or negative) on the social impact of an algorithmic system until after it has been deployed. Regular re-evaluation of all aspects of algorithm systems, and the extent to which they achieve their goals, including pro-ethical Design approaches, will be crucial. Hence, further qualitative research and empirical testing will be needed to understand in detail the benefits, and drawbacks, as well as the practicalities of Ethics as a Service. This will be our next task.

Funding Funding for JM was provided by Digital Catapult and a Wellcome Trust Doctoral Fellowship.

Open Access This article is licensed under a Creative Commons Attribution 4.0 International License, which permits use, sharing, adaptation, distribution and reproduction in any medium or format, as long as you give appropriate credit to the original author(s) and the source, provide a link to the Creative Commons licence, and indicate if changes were made. The images or other third party material in this article are included in the article's Creative Commons licence, unless indicated otherwise in a credit line to the material. If material is not included in the article's Creative Commons licence and your intended use is not permitted by statutory regulation or exceeds the permitted use, you will need to obtain permission directly from the copyright holder. To view a copy of this licence, visit http://creativecommons.org/licen ses/by/4.0/.

\section{References}

Aitken, M., Tully, M. P., Porteous, C., Denegri, S., Cunningham-Burley, S., Banner, N., Black, C., Burgess, M., Cross, L., Van Delden, J., Ford, E., Fox, S., Fitzpatrick, N., Gallacher, K., Goddard, C., Hassan, L., Jamieson, R., Jones, K. H., Kaarakainen, M., ... Willison, D. J. (2019). Consensus statement on public involvement and engagement with data-intensive health research. International Journal of Population Data Science. https://doi.org/10.23889/ijpds.v4i1.586

Aïvodji, U., Arai, H., Fortineau, O., Gambs, S., Hara, S., Tapp, A. (2019). 'Fairwashing: The Risk of Rationalization', 240-52. 36th International Conference on Machine Learning, ICML 2019

Alglorithm Watch. (2020, April 30). AI Ethics Guidelines Global Inventory. Algorithm Watch. https:// inventory.algorithmwatch.org/

Allen, C., Varner, G., \& Zinser, J. (2000). Prolegomena to any future artificial moral agent. Journal of Experimental \& Theoretical Artificial Intelligence, 12(3), 251-261. https://doi.org/10.1080/09528 130050111428

Alshammari, M., \& Simpson, A. (2017). Towards a principled approach for engineering privacy by design. In E. Schweighofer, H. Leitold, A. Mitrakas \& K. Rannenberg (Eds.), Privacy technologies and policy (Vol. 10518, pp. 161-177). https://doi.org/10.1007/978-3-319-67280-9_9

Ananny, M., \& Crawford, K. (2018). Seeing without knowing: Limitations of the transparency ideal and its application to algorithmic accountability. New Media \& Society, 20(3), 973-989. https://doi.org/ $10.1177 / 1461444816676645$ 
Arnold, T., \& Scheutz, M. (2018). The "big red button" is too late: An alternative model for the ethical evaluation of AI systems. Ethics and Information Technology, 20(1), 59-69. https://doi.org/10.1007/ s10676-018-9447-7

Arvan, M. (2018). Mental time-travel, semantic flexibility, and A.I. ethics. AI \& SOCIETY. https://doi. org/10.1007/s00146-018-0848-2

Baum, S. D. (2017). Social choice ethics in artificial intelligence. AI \& SOCIETY. https://doi.org/10. 1007/s00146-017-0760-1

Binns, R. (2018). Algorithmic accountability and public reason. Philosophy \& Technology, 31(4), 543556. https://doi.org/10.1007/s13347-017-0263-5

Brundage, M., Avin, S., Wang, J., Belfield, H., Krueger, G., Hadfield, G., Khlaaf, H., Yang, J., Toner, H., Fong, R., Maharaj, T., Koh, P. W., Hooker, S., Leung, J., Trask, A., Bluemke, E., Lebensold, J., O'Keefe, C., Koren, M., ... Anderljung, M. (2020). Toward trustworthy AI development: Mechanisms for supporting verifiable claims. arXiv:2004.07213

Buhmann, A., Paßmann, J., \& Fieseler, C. (2019). Managing algorithmic accountability: Balancing reputational concerns, engagement strategies, and the potential of rational discourse. Journal of Business Ethics. https://doi.org/10.1007/s10551-019-04226-4

Butcher, J., \& Beridze, I. (2019). What is the state of artificial intelligence governance globally? The RUSI Journal, 164(5-6), 88-96. https://doi.org/10.1080/03071847.2019.1694260

Cath, C. (2018). Governing artificial intelligence: Ethical, legal and technical opportunities and challenges. Philosophical Transactions of the Royal Society A: Mathematical, Physical and Engineering Sciences, 376(2133), 20180080. https://doi.org/10.1098/rsta.2018.0080

Clarke, R. (2019). Principles and business processes for responsible AI. Computer Law and Security Review. https://doi.org/10.1016/j.clsr.2019.04.007

Durante, M. (2015). The democratic governance of information societies. A critique to the theory of stakeholders. Philosophy \& Technology, 28(1), 11-32. https://doi.org/10.1007/ s13347-014-0162-y

Epstein, Z., Payne, B. H., Shen, J. H., Hong, C. J., Felbo, B., Dubey, A., Groh, M., Obradovich, N., Cebrian, M., \& Rahwan, I. (2018). TuringBox: An experimental platform for the evaluation of AI systems. Proceedings of the Twenty-Seventh International Joint Conference on Artificial Intelligence. https://doi.org/10.24963/ijcai.2018/851

Fazelpour, S., \& Lipton, Z. C. (2020). Algorithmic fairness from a non-ideal perspective (pp. 57-63). Scopus. https://doi.org/10.1145/3375627.3375828

Floridi, L. (2013). Distributed morality in an information society. Science and Engineering Ethics, 19(3), 727-743. https://doi.org/10.1007/s11948-012-9413-4

Floridi, L. (2016). Faultless responsibility: On the nature and allocation of moral responsibility for distributed moral actions. Philosophical Transactions of the Royal Society A: Mathematical, Physical and Engineering Sciences, 374(2083), 20160112. https://doi.org/10.1098/rsta.2016. 0112

Floridi, L. (2018). Soft ethics, the governance of the digital and the General Data Protection Regulation. Philosophical Transactions. Series A, Mathematical, Physical, and Engineering Sciences, 376(2133), 1-8. https://doi.org/10.1098/rsta.2018.0081

Floridi, L. (2019a). The logic of information: A theory of philosophy as conceptual design (1st ed.). Oxford University Press.

Floridi, L. (2019b). Translating principles into practices of digital ethics: Five risks of being unethical. Philosophy \& Technology. https://doi.org/10.1007/s13347-019-00354-x

Floridi, L., \& Taddeo, M. (2016). What is data ethics? Philosophical Transactions of the Royal Society A: Mathematical, Physical and Engineering Sciences, 374(2083), 20160360. https://doi.org/ 10.1098/rsta.2016.0360

Floridi, L., \& Cowls, J. (2019). A unified framework of five principles for AI in society. Harvard Data Science Review. https://doi.org/10.1162/99608f92.8cd550d1

Floridi, L., \& Strait, A. (2020). Ethical Foresight Analysis: What it is and Why it is Needed? Minds and Machines, 30(1), 77-97. https://doi.org/10.1007/s11023-020-09521-y

Floridi, L., Cowls, J., Beltrametti, M., Chatila, R., Chazerand, P., Dignum, V., Luetge, C., et al. (2018) AI4People-An Ethical Framework for a Good AI Society: Opportunities, Risks, Principles, and Recommendations'. Minds and Machines 28(4), 689-707. https://doi.org/10.1007/ s11023-018-9482-5

Hagendorff, T. (2020). The ethics of AI ethics: An evaluation of guidelines. Minds and Machines, 30(1), 99-120. https://doi.org/10.1007/s11023-020-09517-8 
Heath, J. (2014). Rebooting discourse ethics. Philosophy and Social Criticism, 40(9), 829-866. https://doi.org/10.1177/0191453714545340

Holstein, K., Vaughan, J. W., Daumé III, H., Dudík, M., \& Wallach, H. (2018). Improving fairness in machine learning systems: What do industry practitioners need? arXiv:1812.05239 [Cs]. https:// doi.org/10.1145/3290605.3300830

International AI ethics panel must be independent. (2019). Nature, 572(7770), 415. https://doi.org/ 10.1038/d41586-019-02491-x

Jobin, A., Ienca, M., \& Vayena, E. (2019). The global landscape of AI ethics guidelines. Nature Machine Intelligence, 1(9), 389-399. https://doi.org/10.1038/s42256-019-0088-2

Katyal, S. K. (2019). Private accountability in the age of artificial intelligence. UCLA Law Review, $66(1), 54-141$

Koene, A., Clifton, C., Hatada, Y., Webb, H., \& Richardson, R. (2019). A governance framework for algorithmic accountability and transparency. Publications Office. https://data.europa.eu. https:// doi.org/10.2861/59990

Krishnan, M. (2019). Against interpretability: A critical examination of the interpretability problem in machine learning. Philosophy and Technology. https://doi.org/10.1007/s13347-019-00372-9

Kroll, J. A. (2018). The fallacy of inscrutability. Philosophical Transactions of the Royal Society A: Mathematical, Physical and Engineering Sciences, 376(2133), 20180084. https://doi.org/10. 1098/rsta.2018.0084

Kroll, J. A., Huey, J., Barocas, S., Felten, E., Reidenberg, J., Robinson, D., \& Yu, H. (2017). Accountable Algorithms. University of Pennyslvania Law Review, 165.

Martin, K. (2019). Ethical implications and accountability of algorithms. Journal of Business Ethics, 160(4), 835-850. https://doi.org/10.1007/s10551-018-3921-3

McMillan, D., \& Brown, B. (2019). Against ethical AI. Proceedings of the Halfway to the Future Symposium 2019 on-HTTF 2019 (pp. 1-3). https://doi.org/10.1145/3363384.3363393

Mingers, J., \& Walsham, G. (2010). Toward ethical information systems: The contribution of discourse ethics. MIS Quarterly: Management Information Systems, 34(4), 855-870.

Mittelstadt, B. (2019). Principles alone cannot guarantee ethical AI. Nature Machine Intelligence, 1(11), 501-507. https://doi.org/10.1038/s42256-019-0114-4

Mökander, J., Morley, J., Taddeo, M., \& Floridi, L. (n.d.). Ethics-based auditing of automated decision-making systems: Nature, scope, and limitations. Forthcoming.

Morley, J., Floridi, L., Kinsey, L., \& Elhalal, A. (2019). From what to how: An initial review of publicly available AI ethics tools, methods and research to translate principles into practices. Science and Engineering Ethics, 26(4), 2141-2168. https://doi.org/10.1007/s11948-019-00165-5

Morley, J., Cowls, J., Taddeo, M., \& Floridi, L. (2020). Ethical guidelines for COVID-19 tracing apps. Nature, 582(7810), 29-31. https://doi.org/10.1038/d41586-020-01578-0

Mulgan, G. (2019). AI ethics and the limits of code(s). Digital Agenda. https://medium.com/digitalage nda/ai-ethics-and-the-limits-of-code-s-f76a3961fccf

Orr, W., \& Davis, J. L. (2020). Attributions of ethical responsibility by Artificial Intelligence practitioners. Information Communication and Society. https://doi.org/10.1080/1369118X.2020.17138 42

Oxborough, C., Cameron, E., Rao, A., Birchall, A., Townsend, A., \& Westermann, C. (2019). Explainable AI: Driving Business Value through Greater Understanding. PWC. https://www. pwc.co.uk/audit-assurance/assets/explainable-ai.pdf

Raab, C. D. (2020). Information privacy, impact assessment, and the place of ethics. Computer Law and Security Review. https://doi.org/10.1016/j.clsr.2020.105404

Rahwan, I. (2018). Society-in-the-loop: Programming the algorithmic social contract. Ethics and Information Technology, 20(1), 5-14. https://doi.org/10.1007/s10676-017-9430-8

Raji, I. D., Smart, A., White, R. N., Mitchell, M., Gebru, T., Hutchinson, B., Smith-Loud, J., Theron, D., \& Barnes, P. (2020). Closing the AI accountability gap: Defining an end-to-end framework for internal algorithmic auditing (pp. 33-44). https://doi.org/10.1145/3351095.3372873

Rehg, W. (2015). Discourse ethics for computer ethics: A heuristic for engaged dialogical reflection. Ethics and Information Technology, 17(1), 27-39. https://doi.org/10.1007/s10676-014-9359-0

Robles Carrillo, M. (2020). Artificial intelligence: From ethics to law. Telecommunications Policy. https://doi.org/10.1016/j.telpol.2020.101937

Saleiro, P., Kuester, B., Stevens, A., Anisfeld, A., Hinkson, L., London, J., \& Ghani, R. (2018). Aequitas: A Bias and Fairness Audit Toolkit. arXiv:1811.05577 [Cs] 
Sandvig, C. (2014). Auditing algorithms: Research methods for detecting discrimination on internet platforms. Data and Discrimination: Converting Critical Concerns into Productive Inquiry.

Schiff, D., Biddle, J., Borenstein, J., \& Laas, K. (2020). What's next for AI ethics, policy, and governance? A global overview (pp. 153-158). https://doi.org/10.1145/3375627.3375804

Simonite, T. (2020, August 28). Google Offers to Help Others With the Tricky Ethics of AI. https:// www.wired.com/story/google-help-others-tricky-ethics-ai/

Terzis, P. (2020). Onward for the freedom of others: Marching beyond the AI ethics (pp. 220-229). https://doi.org/10.1145/3351095.3373152

The IEEE Global Intiative on Ethics of Autonomous and Intelligent Systems. Ethically Aligned Design First Edition: A Vision for Prioritizing Human Well-Being with Autonomous and Intelligent Systems. IEEE, 2019. https://ethicsinaction.ieee.org/

Thomsen, K. (2019). Ethics for artificial intelligence, ethics for all. Paladyn, 10(1), 359-363. https:// doi.org/10.1515/pjbr-2019-0029

Ville, V., Kai-Kristian, K., \& Pekka, A. (2019). AI ethics in industry: A research framework. 2505, 49-60

Whittlestone, J., Nyrup, R., Alexandrova, A., \& Cave, S. (2019). The Role and Limits of Principles in AI Ethics: Towards a Focus on Tensions. https://doi.org/10.17863/cam.37097

Winfield, A. F. T., \& Jirotka, M. (2018). Ethical governance is essential to building trust in robotics and artificial intelligence systems. Philosophical Transactions of the Royal Society A: Mathematical, Physical and Engineering Sciences, 376(2133), 20180085. https://doi.org/10.1098/rsta.2018.0085

Publisher's Note Springer Nature remains neutral with regard to jurisdictional claims in published maps and institutional affiliations. 